\title{
Applying Empirical Methods to Assess the Internal Stability of Embankment Dam Cores of Glacial Till
}

\author{
Hans Rönnqvist, Peter Viklander \\ Department of Civil, Environmental and Natural Resources Engineering, Luleå University of Technology, Luleå, \\ Sweden \\ Email: hans.ronnqvist@ltu.se, peter.viklander@Itu.se
}

Received 18 October 2014; revised 15 November 2014; accepted 8 December 2014

Copyright $@ 2015$ by authors and Scientific Research Publishing Inc.

This work is licensed under the Creative Commons Attribution International License (CC BY). http://creativecommons.org/licenses/by/4.0/

(c) (i) Open Access

\section{Abstract}

This paper presents a database of glacial till gradations that are compiled from laboratory internal stability tests from the literature and from core soils of existing dams, some of which have experienced internal erosion. The potential internal instability of these gradations is assessed using empirical methods. Two approaches of evaluation are used: the Kenney-Lau method, which analyzes the shape of the gradation curve; and the Burenkova method, which uses factors of uniformity of the slope of the gradation. Although they include some uncertainties in terms of soils with fines, these methods, which are primarily developed from laboratory studies of sand and gravels, are used in engineering practice to evaluate widely graded soils that include fines, such as glacial tills. This study evaluates the glacial till gradations of the database using these approaches and discusses their applicability and relative predictive success. This study indicates that both the Kenney-Lau method and the Burenkova method have merit, but a closer analysis indicates that the Kenney-Lau approach has relatively better predictive ability based on the glacial till gradations analyzed in this study.

\section{Keywords}

Internal Stability, Internal Erosion, Cores, Glacial Tills, Embankment Dams

\section{Introduction}

Glacial till, which is a moraine deposit that is formed by glacial action, is commonly used to form impervious cores of embankment dams. When designed and constructed properly, glacial till is highly suitable for dam 
cores [1] [2]. However, these cores have a statistically higher frequency of internal erosion incidents than dams with other types of core soils [3] [4]. Typical symptoms of internal erosion include sinkholes and settlements on the crest, increased seepage and cloudy seepage [3] [5]. Internal erosion occurs when soil particles are carried downstream by seepage. ICOLD [6] recognizes four mechanisms of initiation: concentrated leak erosion, backward erosion, contact erosion and suffusion. The overrepresentation of glacial till cores in internal erosion incidents is possibly due to the erodibility of glacial till. One mechanism that may influence internal erosion is suffusion due to internal instability. Suffusion erodes free moving fines inside a soil and can change the geotechnical properties of the soil [6].

Based on engineering practice, Sherard [7] attributed the notably high frequency of sinkhole formations in dams with this type of core to the internal instability of the glacial till. However, few laboratory studies have been performed, and little data are available. Nonetheless, the internal stability of glacial tills has been investigated by Lafleur and Nguyen [8], Wan [9], Moffat et al. [10], Hunter et al. [11] and Lilja et al. [12], who report that instability may indeed occur in glacial tills.

This study compiles a database of 24 gradations of glacial till that includes gradations identified in the literature review of laboratory internal stability tests on glacial tills by Rönnqvist and Viklander [13] (reproduced after [8]-[12]) as well as gradations of glacial till from the cores of existing dams, some of which have experienced internal erosion (reproduced after [14]). This study assesses the potential internal instability of these gradations using empirical methods. Two approaches of evaluation are used: the Kenney-Lau method [15] [16], which analyzes the shape of the gradation curve; and the Burenkova method [17], which uses characteristic values of the slope of the gradation (factors of uniformity). These methods, which are primarily developed from laboratory studies of sand and gravel, are used in engineering practice to analyze widely graded soils that contain fines, such as glacial tills. This may cause some uncertainty. The glacial till gradations of the database are evaluated using these approaches, and their applicability and relative predictive success when they are used to analyze gradations that are different from those that are originally tested are discussed.

\section{Glacial Tills}

Moraine formations are created by the pulling, crushing, mixing and transport forces generated by the advancement and regression of glaciers. Glacial till, which is collected from moraine deposits, has been widely used as fill for the impervious cores of dams [7]. Till is relatively similar throughout the world; is it typically broadly or widely graded with a mixture of contents that ranges from fines to boulders (Figure 1). In the field of dam engineering, ICOLD [18] defines glacial till as "an unsorted material of glacial origin (...) used as foundations and

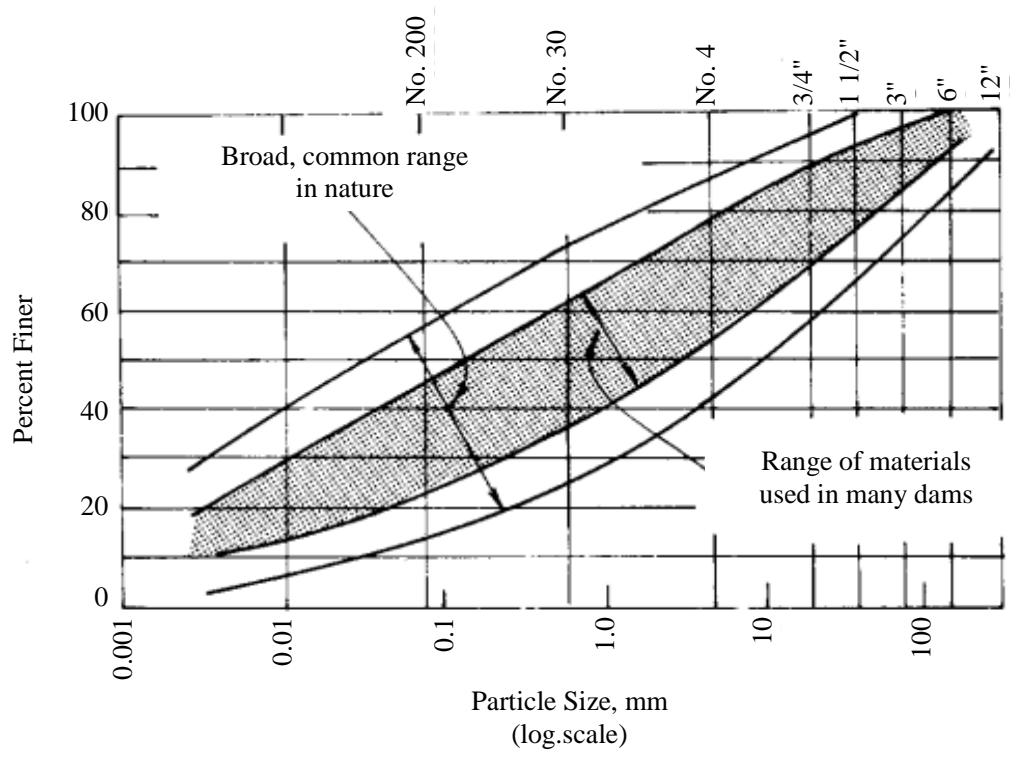

Figure 1. Typical broadly graded glacial soils used as impervious cores in dams (after [21]). 
as the impervious zone of earth and rockfill dams”. ICOLD [18] continues by stating that the composition and grain size distribution generally depend on the source rock and the overburden over which the glacier moves; granite, granitic gneiss and similar hard and massive rocks develop tills with a sandy silt matrix, whereas softer sedimentary rocks, such as limestone and shale, develop a clayey matrix. As reported by Milligan [19], softer sedimentary bedrock in Canada generally forms tills with high plasticity fines (as in the Canadian western prairie provinces), whereas harder igneous and metamorphic bedrock forms tills with non-plastic or low plasticity fines (such as in eastern Canada). Examples from other regions include the clayey matrix of British glacial tills [20] and the low-clay and generally non-plastic glacial tills in Scandinavia [1] [2]. North American glacial tills that are used as dam cores are relatively fines-rich with fines contents of $20 \%$ to $70 \%$. Scandinavian tills typically contain $15 \%$ to $60 \%$ fines, and glacial tills in Russian dams are fines-poor with fines contents of $5 \%$ to $20 \%$ [18]. Fines content is the amount passing the \#200 sieve $(0.075 \mathrm{~mm})$.

\section{Internal Instability and Erosion by Suffusion}

A soil that is internally stable has a gradation in which all of the particles contribute to the skeletal structure of the soil. The gradation is illustrated by the particle size distribution of the soil, which shows the relative amount by mass that is contributed by the soil particles. An unstable gradation has an imbalance in the distribution of particles so that the soil is divided into a coarser fraction and a finer fraction; the coarser fraction becomes structural with few highly stressed particle contacts, whereas the finer fraction is non-structural with no effective stress transfer between grains. Thus, in internally unstable soils, the finer fraction comprises moveable and potentially erodible particles.

\subsection{Geometrical Requirements for Suffusion}

Suffusion is an internal erosion process that is caused by internal instability and involves the "selective erosion of finer particles from the matrix of coarser particles (...) leaving behind a soil skeleton formed by the coarser particles" [6]. For suffusion to occur, the finer fraction of the soil must be less than the available void space in the coarser fraction [22]. A soil that consists predominately of a finer fraction (i.e., a matrix-supported soil) is thus not susceptible to suffusion because the coarser grains are not in grain-to-grain contact but float in the matrix of the finer fraction.

Several opinions on the limit value of the finer fraction for suffusion susceptible soil have been presented in the literature. Wan and Fell [22] argued that the limit is between 22\% and 33\% and is unlikely to be higher than $40 \%$ based on tests on broadly graded samples, while Skempton and Brogan [23] estimated the limit as 35\%. Kenney and Lau [15] empirically determined the limit to be $20 \%$ based on the lost particles of the unstable widely graded soils that they tested. A widely graded soil is most likely not susceptible to suffusion unless the finer fraction is less than approximately $25 \%$ to $35 \%$. According to ICOLD [6], the finer fraction is determined from the inflection point of the gradation; i.e., the change in slope from the initial slope of the coarse fraction to its transition to the finer fraction (Figure 2(a)). This transition may be difficult to identify. Applications of this procedure to fines-rich and fines-poor glacial till gradations are shown schematically in Figure 2(b).

\subsection{Effects of Suffusion}

Although suffusion has been reported to increase the permeability [6], laboratory studies also indicate that suffusion results in clogging with zones of low permeability, increased gradients and pore pressure build-up [8] [24]. Furthermore, Moffat et al. [10] found that suffusion occurred as the "episodic migration of the finer fraction" with no change in volume but a "relatively small and slow change in local hydraulic conductivity".

\section{Internal Stability Criteria}

\subsection{Shape Analysis Methods for Internal Stability Assessment}

Kezdi [25] and Sherard [7] independently proposed theoretical methods to assess internal stability by splitting the gradation into a fine part and a coarse part (i.e., $\mathrm{D}_{15} / \mathrm{d}_{85}=4$ ) to evaluate the self-filtering ability of the soil. However, the split-gradation approaches were not substantiated by laboratory testing. From the outset of the USACE [26] filter experiments, Kenney and Lau [15] [16] studied the internal stability of sand and gravel 


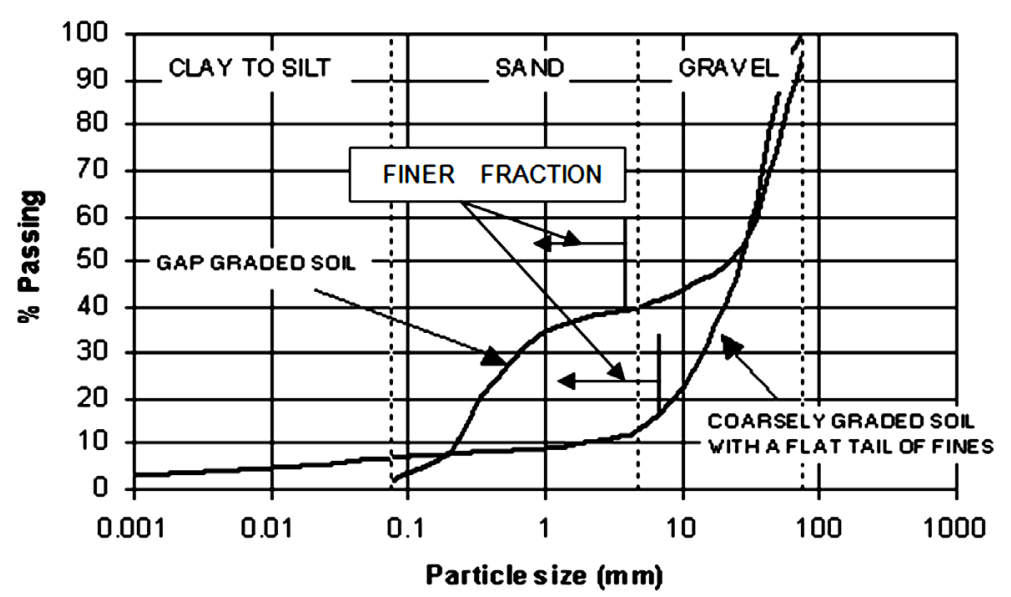

(a)

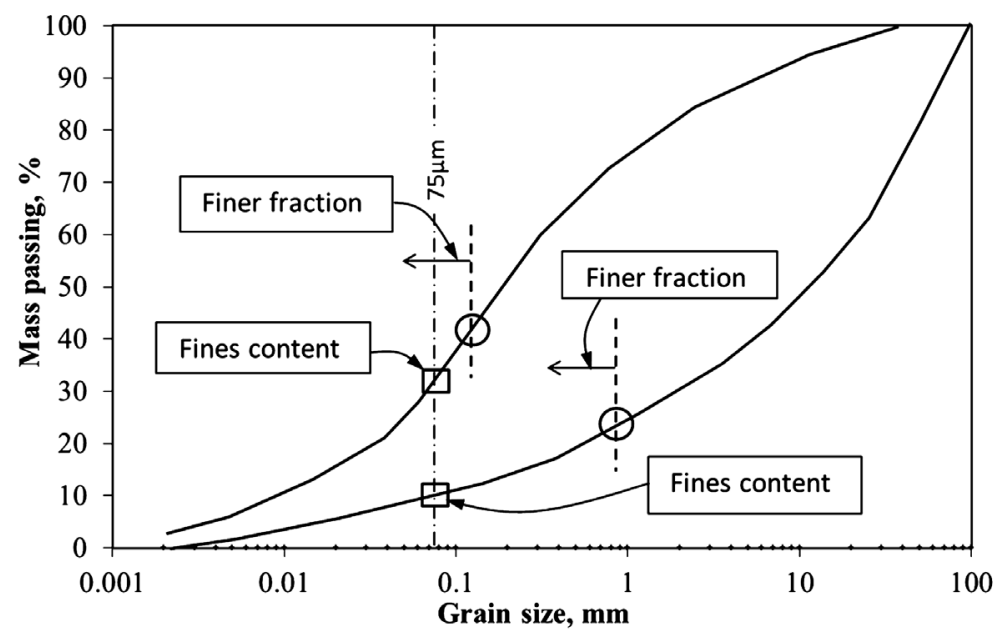

(b)

Figure 2. Determining the finer fraction: (a) Illustration reproduced from ICOLD [6] showing a gap-graded soil and coarsely graded soil; and (b) Schematic showing the application of the ICOLD finer-fraction procedure to fines-rich versus fines-poor glacial till gradations (after [13]).

specimens in a laboratory setting with permeameter experiments, and Li and Fannin [27] adapted it to include the Kezdi [25] split-gradation method. Burenkova [17] used a different approach to study suffusion susceptibility by dry mixing various fractions and identifying volume changes that occur when finer fractions are introduced. However, Wan and Fell [22] discovered that previous attempts to test the internal stability of soils did not include soils with silt or clay; most of the investigations were on cohesionless sand-gravel mixtures or coarse granular materials, so they conducted seepage tests on clay-silt-sand-gravel and silt-sand-gravel mixtures. Wan and Fell [22] subsequently found that the approach of Burenkova [17] provided satisfactory predictions when analyzing specimens that contain silt.

The approaches by Kenney and Lau [15] [16] and Burenkova [17], with the respective adaptations by Li and Fannin [27] and Wan and Fell [22] [28], are discussed further in the following sections.

\subsection{The Kenney-Lau Method and Li-Fannin Adaptation}

Based on tests of cohesionless sands and gravels that contain particles up to $100 \mathrm{~mm}$ without a silt fraction, Kenney and Lau [15] concluded that soils that experience a loss of fine-grained particles have unstable gradations and conversely that the gradation is stable where there is no loss of particles. Kenney and Lau [15] [16] then proposed a method for evaluating the potential for grading instability; they deduced stable versus unstable 
gradations based on the shape of the particle size distribution with a limiting-shape curve of $\mathrm{H}=1.0 \mathrm{~F}$. The method involves determining the mass fraction of particle sizes between $\mathrm{D}$ and $4 \mathrm{D}$ (denoted by $\mathrm{H}$ ) and the passing weight at the particle size D (i.e., F); a deficiency in the number of particles of a certain fraction (between D and 4D) will potentially allow for the erosion of particles that are finer than D. For widely graded materials $\left(C_{u}>3\right)$, the evaluation range is passing weights of 0 to $20 \%$, which is the maximum range for loose particles in such a soil according to Kenney and Lau [15]. Thus, a stability index H/F of less than one indicates that a soil is deficient in the finer fraction and is potentially internally unstable. The evolution of the Kenney and Lau approach is covered in Rönnqvist and Viklander [29].

$\mathrm{Li}$ and Fannin [27] proposed extending the approach of Kenney and Lau [15] [16] to include the criterion of Kezdi [25]. These methods are similar; both examine the slope of the grading curve over a certain length. As reported by Li and Fannin [27], the Kezdi criterion is incremental over the percentage that is finer by mass, whereas the Kenney-Lau criterion is incremental over the grain size. Figure 3 shows the application of the Kenney-Lau method and Li-Fannin adaptation and how to generate the stability index $(\mathrm{H} / \mathrm{F})_{\min }$ from the H:Fshape curve.

\subsection{The Burenkova Method and Wan-Fell Adaptations}

Burenkova [17], who tested cohesionless sand-gravel soils with $C_{u}=d_{60} / d_{10}$ values up to 200 and particle sizes up to $100 \mathrm{~mm}$ and some silt fractions (less than $10 \%$ fines), dry mixed a coarse fraction while gradually introducing a finer fraction. No net change to the volume of the sample indicated that the finer fraction was part of the loose particles and thus susceptible to suffusion. Conversely, an increase in volume would indicate that the finer fraction belongs to the soil skeleton and is therefore structural; thus, it is not susceptible to suffusion. Three soil grain sizes (i.e., $\mathrm{d}_{90}, \mathrm{~d}_{60}$ and $\mathrm{d}_{15}$ ) were identified, and a predictive method for assessing the suffusive or non-suffusive characteristics of soils were proposed by combining these sizes into factors of uniformity h' and h" (i.e., $\mathrm{d}_{90} / \mathrm{d}_{15}$ and $\mathrm{d}_{90} / \mathrm{d}_{60}$, respectively), which define the boundaries for suffusive and non-suffusive soils (Figure 4) [17].

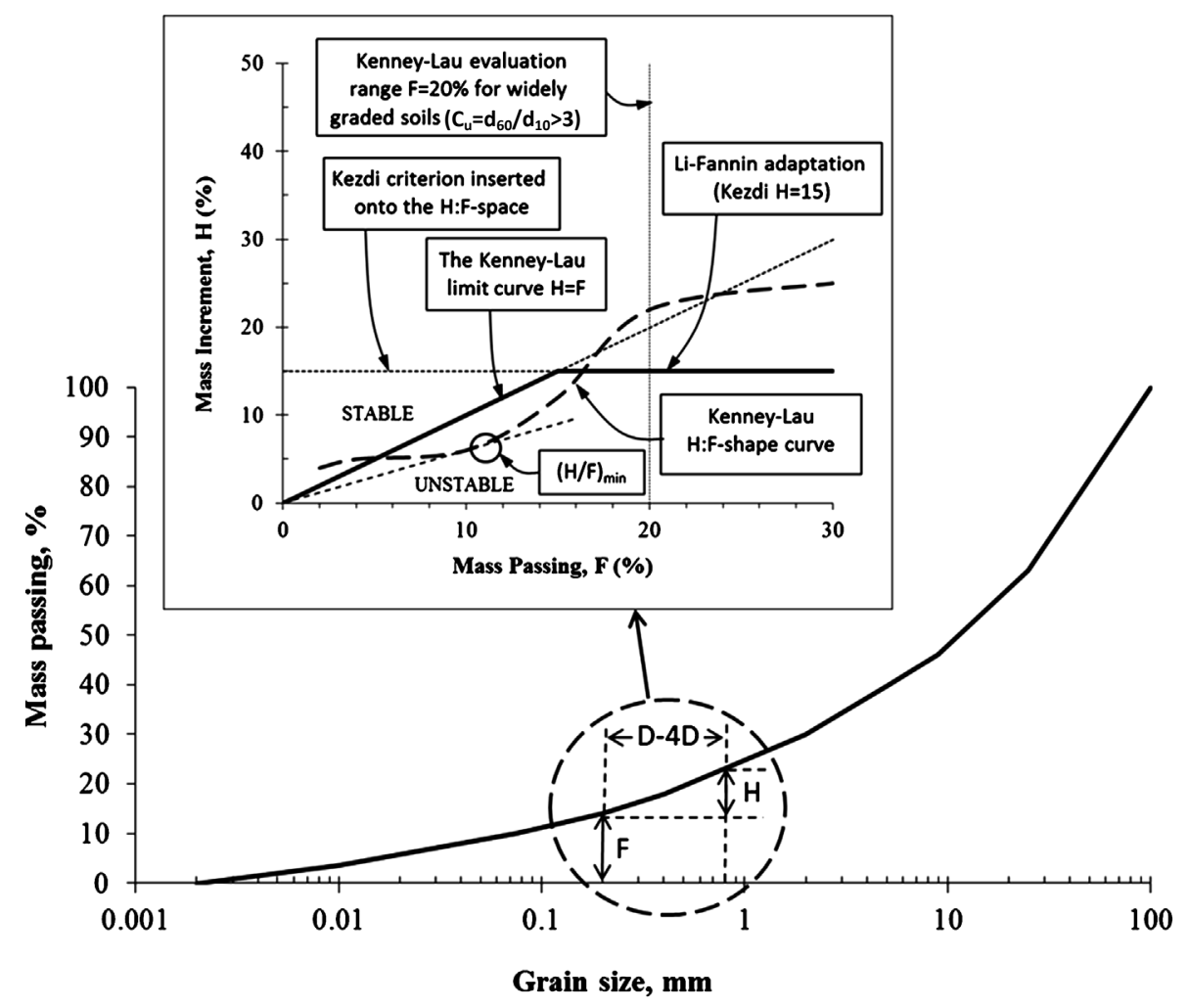

Figure 3. Illustration of the Kenney-Lau method. The inset shows the H:F-shape curve and stability index and the Li-Fannin adaptation (adapted after [15] [16] [27]). 


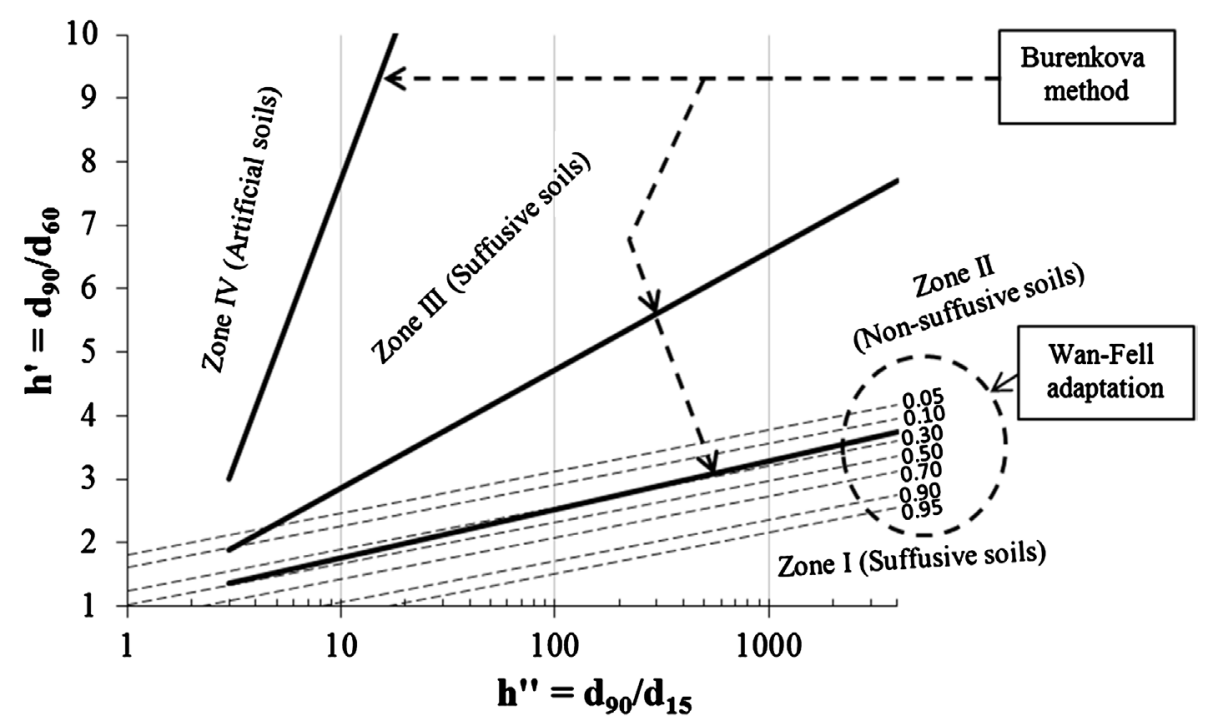

Figure 4. Illustration of the Burenkova method with the Wan-Fell adaptation with contours of the probability of internal instability superimposed (adapted after [17] [22]).

Based on downward and upward flow seepage tests on clay-silt-sand-gravel and silt-sand-gravel mixtures that are rich in fines, Wan and Fell [22] determined that the Burenkova method gave reasonable correlations to their seepage tests. They adapted the method to include a probabilistic approach that incorporated contours of the probability of internal instability (Figure 4). When the Wan-Fell [22] contours are superimposed over the Burenkova [17] boundaries and zones (Figure 4), the Wan-Fell adaptation is shown to partly cross over into the Burenkova non-suffusive zone.

Wan and Fell [28] subsequently proposed an alternative method for broadly graded soils. They found that gradations that are uniformly graded in the coarse fraction (i.e., steep slope) and broadly graded in the finer fraction (i.e., flat slope) were likely to be internally unstable but were not necessarily predicted to be by the Burenkova method. This alternative method uses the same characteristic $\mathrm{D}_{90} / \mathrm{D}_{60}$ value for the coarser fraction but combines it with a value of $\mathrm{D}_{20} / \mathrm{D}_{5}$ for the finer fraction.

\section{Database of Glacial Till Gradations}

\subsection{Experimental Database of Gradations}

In a literature review of laboratory internal stability tests, five studies that involved glacial tills and laboratory suffusion tests were identified [13]. These were the investigations by Lafleur and Nguyen [8], Wan [9], Moffat et al. [10], Hunter et al. [11], and Lilja et al. [12], which all incorporated glacial till samples that were either related to, or directly sourced from, dam core zones or transitions.

Compiling these gradations results in an experimental database that includes 11 gradations (Figure 5), whose characteristics are summarized in Table 1; of these, seven gradations are internally unstable according to laboratory tests (i.e., S7, S10, C-20, C-30, CG3, Mr3 and Mr19). Using seepage tests with a gradient of 10, Lafleur and Nguyen [8] found that cohesionless broadly graded glacial tills with fines content up to $12 \%$ (with $D_{\max }$ of $38 \mathrm{~mm}$ ) were susceptible to suffusion, but tills with higher fines content were not susceptible (Table 1). Wan [9] found that when subjected to a constant gradient of 8 , a glacial till with $20 \%$ fines (with $D_{\max }$ of $4.75 \mathrm{~mm}$ ) is not susceptible to suffusion. Moffat and Fannin [10] [30] observed suffusive characteristics in a glacial soil with non-plastic fines up to $30 \%$ (with $\mathrm{D}_{\max }$ of $20 \mathrm{~mm}$ ). Furthermore, based on seepage tests, Lilja et al. [12] reported internal instability in glacial tills with fines between $25 \%$ to $35 \%$ (with $\mathrm{D}_{\max }$ of $30 \mathrm{~mm}$ ). While investigating global backward erosion, Hunter et al. [11] found that the coarse test grading CG3 experienced backward erosion but concluded that suffusion most likely indirectly influenced the process.

\section{Characteristics of Gradations}

The studied gradations comprise glacial till soils with the fines content (passing $0.075 \mathrm{~mm}$ when regraded on the 


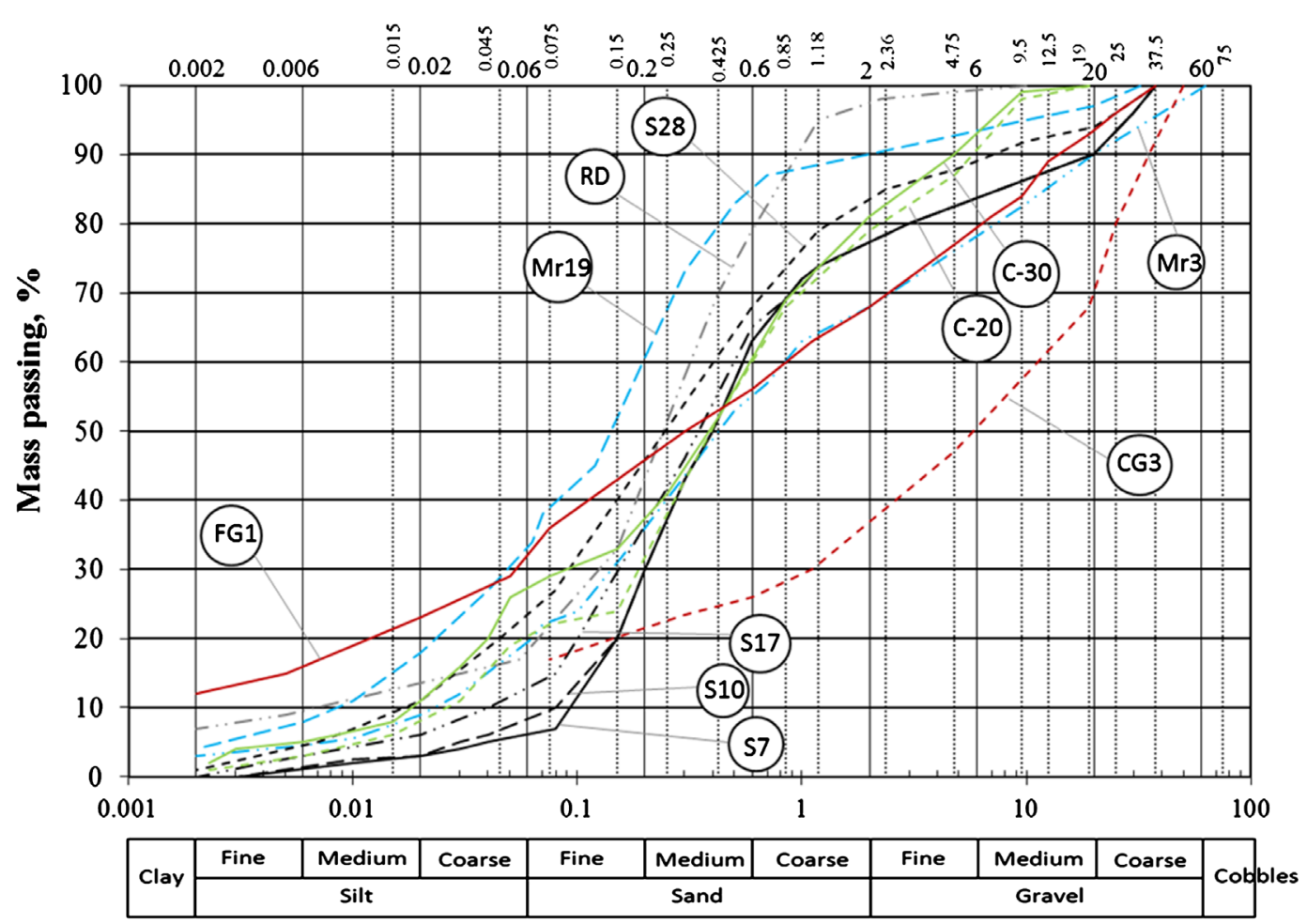

Grain size, $\mathbf{m m}$

Figure 5. Compilation of glacial till gradations from laboratory internal stability tests (after [13]).

Table 1. Characteristics of gradations from the cores of existing dams.

\begin{tabular}{|c|c|c|c|c|c|c|}
\hline Source & Gradation & $\mathrm{D}_{\max }(\mathrm{mm})$ & Fines content $(\%)^{\mathrm{a}}$ & Finer fraction $(\%)^{\mathrm{b}}$ & $\mathrm{C}_{\mathrm{u}}=\mathrm{d}_{60} / \mathrm{d}_{10}$ & Summary of test results \\
\hline \multirow{4}{*}{ Lafleur and Nguyen [8] } & S28 & 37.5 & $28(36)$ & 38 & 24 & Stable \\
\hline & S17 & 37.5 & $17(20)$ & 37 & 13 & Stable \\
\hline & S10 & 37.5 & $10(12)$ & 33 & 6 & Unstable \\
\hline & S7 & 37.5 & 7 (8) & 25 & 6 & Unstable \\
\hline Wan [9] & $\mathrm{RD}$ & 9.5 & $22(23)$ & 45 & 49 & Stable \\
\hline \multirow{2}{*}{ Moffat et al. [10] } & $\mathrm{C}-20$ & 19 & $20(26)$ & 20 & 20 & Unstable \\
\hline & C-30 & 19 & $30(33)$ & 35 & 30 & Unstable \\
\hline \multirow{2}{*}{ Hunter et al. [11] } & FG1 & 37.5 & $33(43)$ & 40 & 425 & Stable \\
\hline & CG3 & 53 & $17(36)$ & 25 & 147 & Unstable \\
\hline \multirow{2}{*}{ Lilja et al. [12] } & Mr3 & 63 & $22(29)$ & 32 & 40 & Unstable \\
\hline & Mr19 & 31.5 & $38(41)$ & 38 & 25 & Unstable \\
\hline
\end{tabular}

${ }^{\mathrm{a}}$ Mass passing $0.075 \mathrm{~mm}$ of the full sample; brackets indicate that it is regraded to $\# 4$ sieve (i.e., $4.75 \mathrm{~mm}$ ); ${ }^{\mathrm{b}}$ Point of inflection on the gradation curve.

$4.75 \mathrm{~mm}$ sieve) of $8 \%$ to $43 \%$ and coefficients of uniformity $\left(C_{u}=d_{60} / d_{10}\right)$ of 6 to 425 (Table 1$)$. Several of the gradations have finer fractions that exceed 35\% (i.e., gradations S28, S17, RD, FG1, and Mr19) and are thus potentially not susceptible to suffusion. This will be addressed in the analyses in the following sections.

\subsection{Database of Existing Dams with Cores of Glacial Till}

In a study of the possibility of extending the Kenney-Lau method [15] [16] to gradations that include a fraction 
of non-cohesive silt, specifically glacial till, the gradations of the core soil of glacial till belonging to 74 existing dams were analyzed [14]. Performance monitoring data described in published and unpublished reports were used to identify 23 of the dams in which internal erosion has been documented; the other 51 dams have no records of deficiencies that can be reasonably attributed to internal erosion. Thus, the dams were sorted into 1) dams with the probable occurrence of internal erosion, and 2) dams with no observations that indicate internal erosion.

\subsubsection{Reducing the Influence of the Filter}

The comparative analysis was performed on dams within the same range of filter coarseness to minimize the influence of the filter (i.e., filter $\mathrm{D}_{15}$ ) on internal erosion and increase the influences of the core and a potential subordinate cause of internal erosion (e.g., core internal instability) [14].

Foster and Fell [31] advocate three empirical boundaries for soil retention: a No Erosion (NE) boundary, an Excessive Erosion (EE) boundary, and a Continuing Erosion (CE) boundary. A Some Erosion zone with base soil retention is located between the NE and EE boundaries. This zone, which varied between $\mathrm{D}_{15}=0.7 \mathrm{~mm}$ and approximately $6 \mathrm{~mm}$ for the analyzed gradations in this study, was present in 44 of the 74 dams, thus distinguishing a group of dams within the same filter coarseness range [14].

\subsubsection{Select Gradations for Analysis}

Given that neither soils with excessive finer fraction nor glacial till with excessive fines content are susceptible to suffusion [6] [8], the population of dams was screened accordingly. Thirteen dams remained after screening out dams with finer content $>35 \%$ and fines content $>30 \%$ (based on the average values obtained from the soil's gradation envelope); these dams have thus gradations that are possibly susceptible to suffusion. Five are dams with performance history of internal erosion (i.e., probable occurrence of internal erosion) (Table 2, Table $3)$. The gradation analyses established the most vulnerable gradation curve of the available grain size distributions for each dam (Figure 6, Table 2).

\subsubsection{Characteristics of Gradations}

The soils are cohesionless glacial tills with low to zero clay content and non-plastic or low-plasticity fines. Gradations denoted A, L, N, P and S represent dams considered to have a probable occurrence of internal erosion

Table 2. Characteristics of gradations from existing dam cores.

\begin{tabular}{|c|c|c|c|c|c|c|}
\hline Source & Denotation & $\mathrm{D}_{\max }(\mathrm{mm})$ & Fines content $(\%)^{\mathrm{a}}$ & Finer fraction $(\%)^{\mathrm{b}}$ & $\mathrm{C}_{\mathrm{u}}=\mathrm{d}_{60} / \mathrm{d}_{10}$ & $\begin{array}{l}\text { Performance in terms } \\
\text { of internal erosion }\end{array}$ \\
\hline \multirow{13}{*}{$\begin{array}{l}\text { Rönnqvist and } \\
\text { Viklander [14] }\end{array}$} & 4 & 16 & $16(21)$ & 30 & 40 & No observations ${ }^{c}$ \\
\hline & 11 & 16 & $10(11)$ & 20 & 8 & No observations ${ }^{c}$ \\
\hline & 17 & 16 & $32(35)$ & 28 & 39 & No observations ${ }^{\mathrm{c}}$ \\
\hline & 22 & 16 & $24(28)$ & 39 & 75 & No observations ${ }^{\mathrm{c}}$ \\
\hline & 26 & 16 & $18(21)$ & 28 & 30 & No observations ${ }^{c}$ \\
\hline & 37 & 64 & $38(54)$ & 32 & 133 & No observations ${ }^{c}$ \\
\hline & 45 & 128 & $11(15)$ & 16 & 19 & No observations $^{c}$ \\
\hline & 54 & 64 & $18(35)$ & 21 & 133 & No observations ${ }^{\mathrm{c}}$ \\
\hline & A & 150 & $32(53)$ & 33 & 1357 & Probable occurrence ${ }^{\mathrm{d}}$ \\
\hline & $\mathrm{L}$ & 20 & $19(24)$ & 35 & 60 & Probable occurrence ${ }^{\mathrm{d}}$ \\
\hline & $\mathrm{N}$ & 150 & $20(34)$ & 28 & 200 & Probable occurrence \\
\hline & $\mathrm{P}$ & 16 & $12(16)$ & 35 & 32 & Probable occurrence $e^{\mathrm{d}}$ \\
\hline & S & 180 & $11(18)$ & 35 & 53 & Probable occurrence \\
\hline
\end{tabular}

${ }^{\mathrm{a}}$ Mass passing $0.075 \mathrm{~mm}$ of the full sample; brackets indicate that it is regraded to \#4 sieve (i.e., $4.75 \mathrm{~mm}$ ); ${ }^{\mathrm{b}}$ Point of inflection on the gradation curve; ${ }^{\mathrm{c}}$ No observations to indicate internal erosion; ${ }^{\mathrm{d}}$ Probable occurrence of internal erosion. 
Table 3. Summary of performance record in terms of internal erosion for dams with probable occurrence of internal erosion.

\begin{tabular}{|c|c|c|c|c|}
\hline Source & Denotation & $\begin{array}{l}\text { Dam and year } \\
\text { of completion }\end{array}$ & Country & Performance record \\
\hline \multirow{5}{*}{$\begin{array}{l}\text { Rönnqvist and } \\
\text { Viklander [14] }\end{array}$} & A & Hytteljuvet (1965) & Norway & $\begin{array}{l}\text { Muddy discharge upon first filling and subsequently over time, } \\
\text { and a sinkhole incident in 1972. Exploratory borings showed } \\
\text { locally large flows [32] [33]. }\end{array}$ \\
\hline & $\mathrm{L}$ & Lövön (1973) & Sweden & $\begin{array}{l}\text { Sinkhole incidents in } 1983 \text { and 1986. Investigations showed a } \\
\text { loss of fines in the core, loose zones, cavities and elevated pore } \\
\text { pressures, as well as signs of suffused and piped core materials } \\
\text { and clogging of fines against the filter face [4] [34]. }\end{array}$ \\
\hline & $\mathrm{N}$ & Viddalsvattn (1971) & Norway & $\begin{array}{l}\text { Increased seepage flow with muddy discharge upon first filling } \\
\text { and subsequently over time and a sinkhole incident in } 1973 \text { [35]. }\end{array}$ \\
\hline & $\mathrm{P}$ & Porjus (1975) & Sweden & $\begin{array}{l}\text { Sinkhole incident upon first filling and sinkhole incidents in 1979, } \\
1985 \text { and } 1993 \text { with increased seepage flow. Investigations showed } \\
\text { erosion of the core and high pore pressures in the filter [4] [36]. }\end{array}$ \\
\hline & S & Songa (1962) & Norway & $\begin{array}{l}\text { Muddy discharge in } 1991 \text { and settlement on the crest. Investigations } \\
\text { showed loose zones in the core and zones of water loss [37]. }\end{array}$ \\
\hline
\end{tabular}

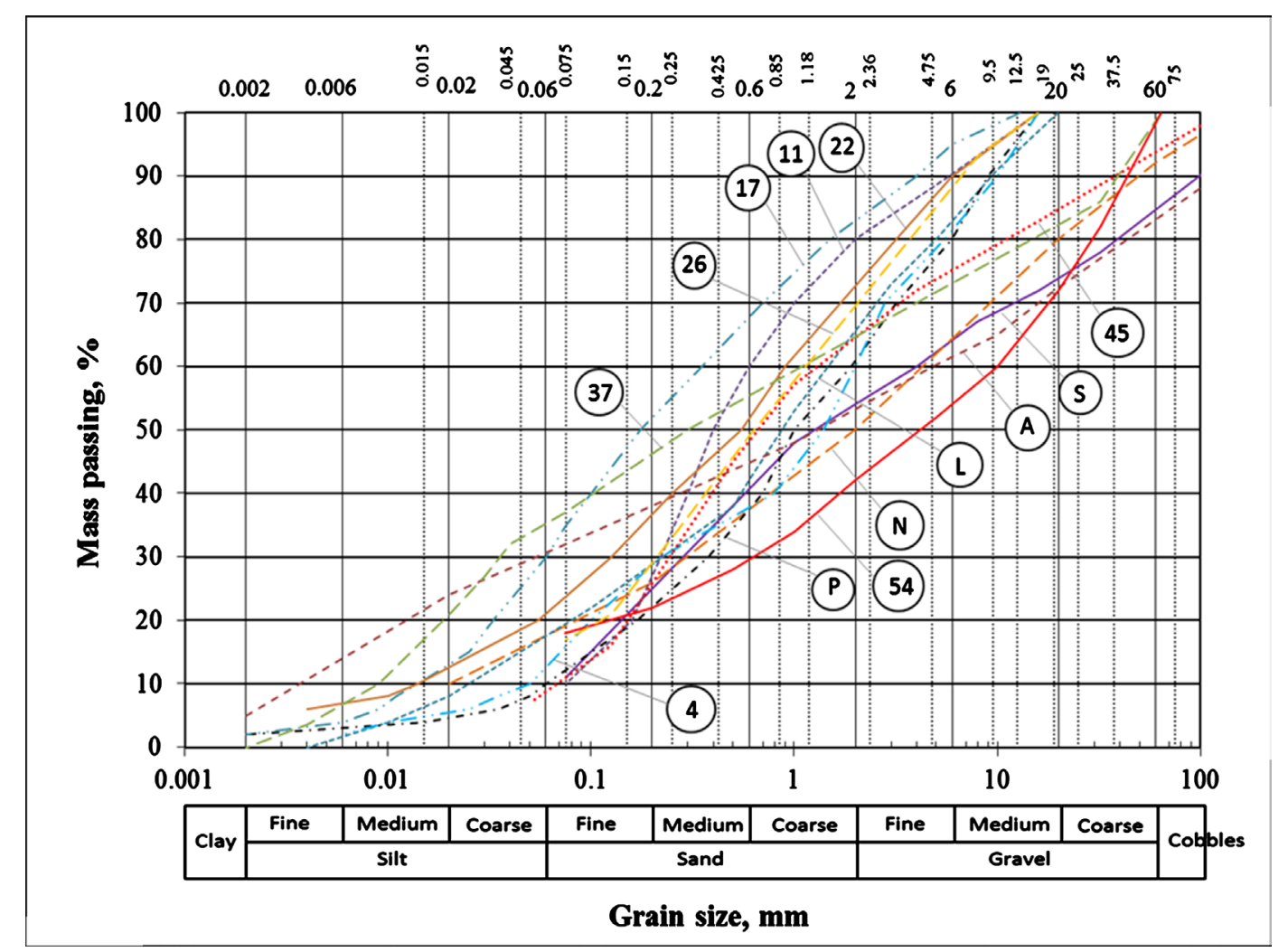

Figure 6. Compilation of glacial till gradations from cores of existing dams, some of which have experienced internal erosion (after [14]).

(Table 2). Details of the performance record for these dams reveals incidents of high piezometric water levels, increased seepage flow, and muddy discharge, in many cases accompanied by sinkhole activity; all of these are indications of probable occurrence of internal erosion (Table 3).

The fines content (passing $0.075 \mathrm{~mm}$ when regraded on the $4.75 \mathrm{~mm}$ sieve) of the glacial tills varies from $11 \%$ to $54 \%$ with coefficients of uniformity ranging from 8 to 1357 (Table 2). One of the gradations has a finer fraction greater than 35\% (39\%; gradation 22) and is thus potentially not susceptible to suffusion. This will be addressed in the analyses in the following sections. 


\section{Empirical Analysis of Internal Instability Using Existing Methods}

\subsection{The Kenney-Lau Approach}

The Kenney-Lau method [15] [16] evaluates the potential for internal stability by analyzing the shape of the finer end of the gradation curve. The Li-Fannin adaptation [27] incorporates the Kezdi [25] split-gradation method. The H:F-shape curves of the most vulnerable core gradations are shown in Figure 7, and the corresponding stability indexes (i.e., $\mathrm{H} / \mathrm{F}_{\min }$ ) are shown in Figure 8(a). The stability index is the smallest value along the $\mathrm{H}: \mathrm{F}$ curve within the evaluation range is mass passing 0 to $20 \%$ (for widely graded materials, $C_{u}=d_{60} / d_{10}>3$ ), as indicated in Figure 7 and Figure 8).

A summary of the analyses (Table 4) shows that the Kenney-Lau method identifies $75 \%$ of the unstable gradations and that $56 \%$ of the potentially unstable gradations are gradations that tested or performed as unstable (Figure 8(a)). Disregarding the gradations with finer fraction $>35 \%$ (not susceptible to suffusion), 82\% of the unstable gradations were identified. The equivalent values for the Li-Fannin adaptation are $67 \%$ and $67 \%$, respectively (Figure 8(b), Table 4).

\subsection{The Burenkova Approach}

The Burenkova method [17] evaluates the potential for internal instability using a characteristic value for the slope of the coarser fraction $\left(\mathrm{D}_{90} / \mathrm{D}_{60}\right)$ and the overall slope of the gradation curve $\left(\mathrm{D}_{90} / \mathrm{D}_{15}\right)$. The Wan-Fell adaptation [22] incorporates a probabilistic approach within the same framework of the grain size ratio. The distribution of gradations from the Burenkova method is given in Figure 9, and the distribution from the Wan-Fell adaptation is shown in Figure 10.

A summary of the analyses (Table 4) of the most vulnerable core gradations shows that the Burenkova method identifies $58 \%$ of the unstable gradations and that $47 \%$ of the potentially unstable gradations are gradations which have tested or performed as unstable (Figure 9). The equivalent values for the Wan-Fell adaptation are 8\% and 50\%, respectively (Figure 10, Table 4) for a greater than 5\% probability of internal instability (for silt-sand-gravel soils and clay-silt-sand-gravel soils with limited clay contents and plasticity).

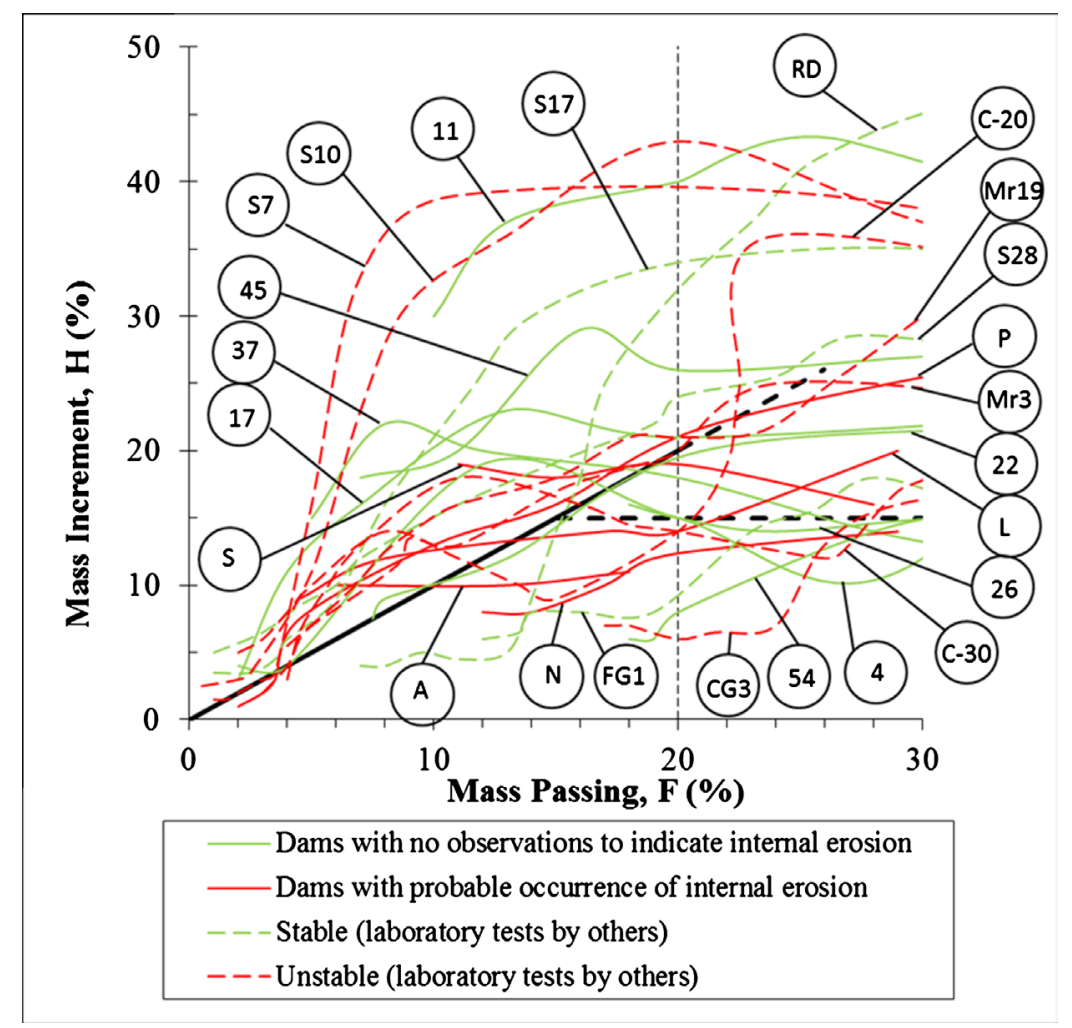

Figure 7. H:F-shape curves obtained by applying the Kenney-Lau method. 


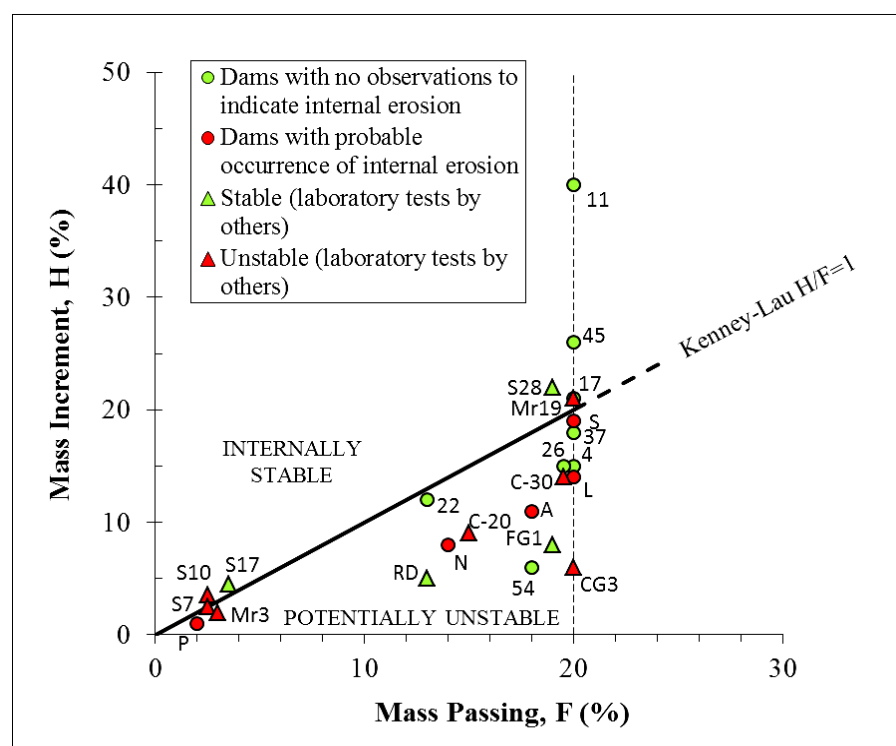

(a)

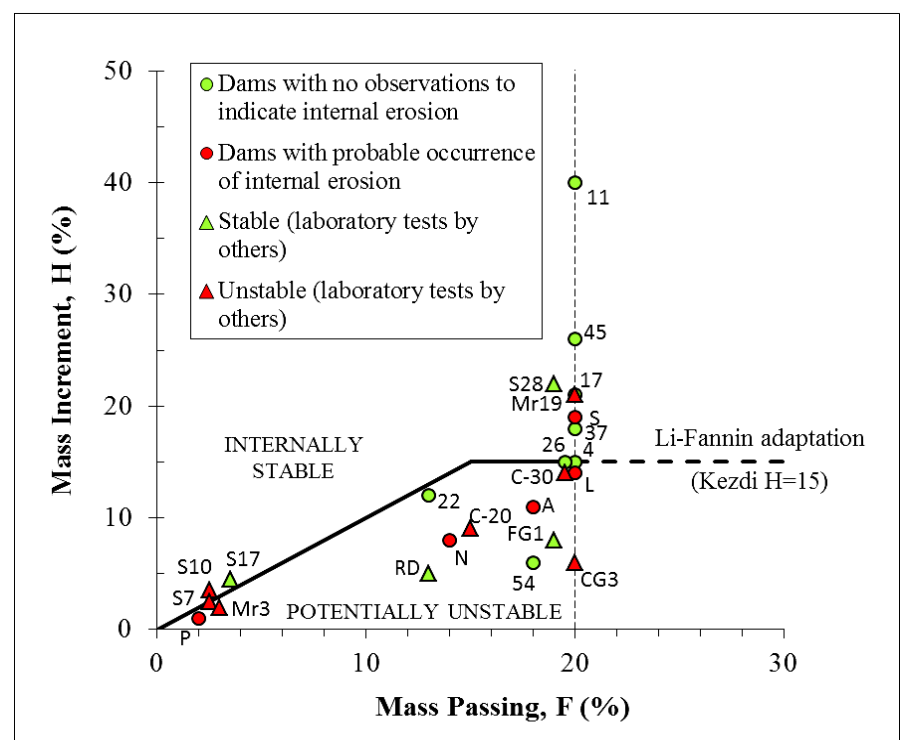

(b)

Figure 8. Stability indexes (H/F) $)_{\min }$ compared to the boundary of (a) the Kenney-Lau method and (b) the Li-Fannin adaptation.

Table 4. Summary of test results from gradation analyses of glacial till core specimens.

\begin{tabular}{lccc}
\hline \multicolumn{1}{c}{ Empirical Criteria } & $\begin{array}{c}\text { Identified unstable } \\
\text { gradations (\%) }\end{array}$ & $\begin{array}{c}\text { Unstable gradations not } \\
\text { identified }\end{array}$ & $\begin{array}{c}\text { Potentially unstable with unstable performance } \\
\text { (either in laboratory tests or in-situ at dams) }\end{array}$ \\
\hline $\begin{array}{l}\text { Kenney-Lau method [15] [16] } \\
\text { Li-Fannin adaptation [27] }\end{array}$ & $75\left(82^{\mathrm{a}}\right)$ & S7, S10, Mr19 & $56\left(69^{\mathrm{a}}\right)$ \\
$\begin{array}{l}\text { Burenkova method } \\
\text { (zone I or III) [17] }\end{array}$ & $67\left(73^{\mathrm{a}}\right)$ & S7, S10, Mr19, S & $67\left(89^{\mathrm{a}}\right)$ \\
$\begin{array}{l}\text { Wan-Fell adaptation } \\
(>5 \% \text { probability) [22] }\end{array}$ & $58\left(55^{\mathrm{a}}\right)$ & S7, S10, Mr3, CG3, A & $47\left(55^{\mathrm{a}}\right)$ \\
$\begin{array}{l}\text { Wan-Fell alternative method [28] } \\
8\left(9^{\mathrm{a}}\right)\end{array}$ & $\begin{array}{c}\text { S7, S10, Mr3, Mr19, C-20, } \\
\text { C-30, A, L, N, P, S } \\
\text { S7, S10, Mr3, Mr19, C-20, } \\
\text { C-30, A, L, P }\end{array}$ & $50\left(50^{\mathrm{a}}\right)$ \\
\hline
\end{tabular}

${ }^{\mathrm{a}}$ Results when gradations with finer fraction $>35 \%$ are excluded (i.e., S17, S28, RD, FG1, Mr19 and 22); ${ }^{\mathrm{b}}$ Gradations RD, FG1, CG3, S, N, 11,26 and 54 are not included because gradation data on minus \#200 sieve are not available. 


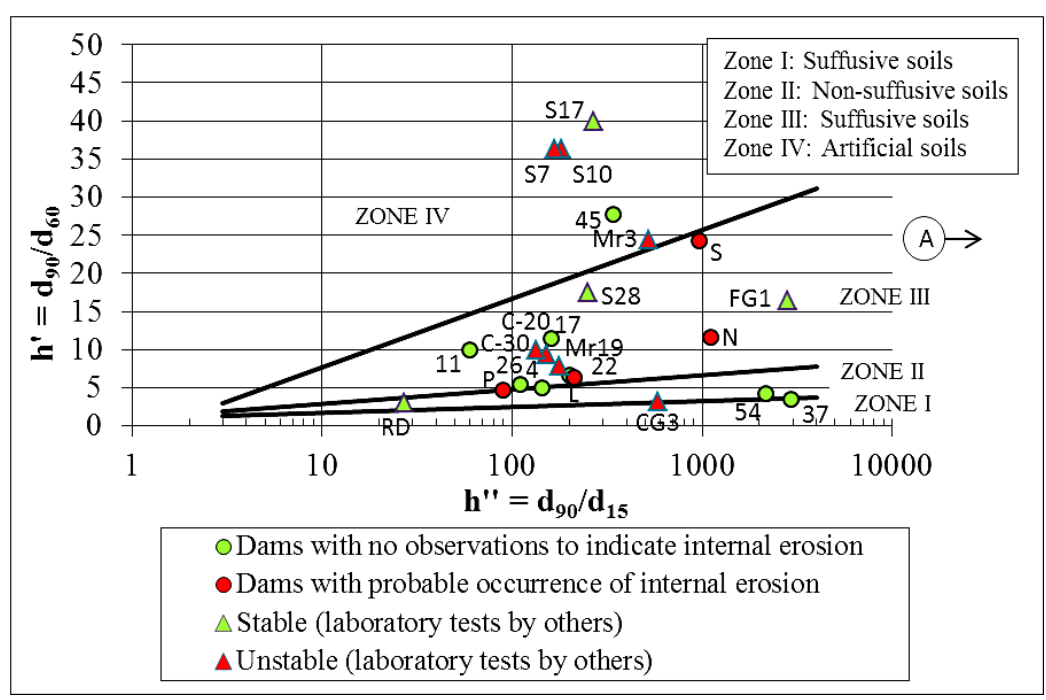

Figure 9. Distribution of gradations obtained by applying the Burenkova method.

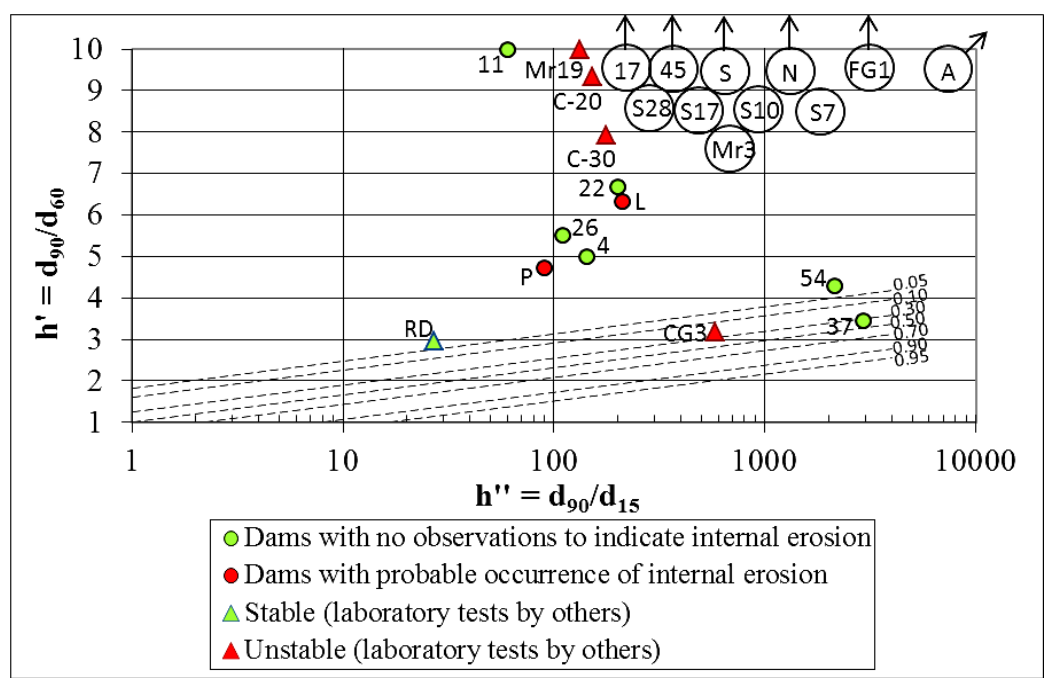

Figure 10. Distribution of gradations obtained by applying the Wan-Fell adaptation with contours of the probability of internal instability.

\subsection{The Wan-Fell Alternative Method}

Recognizing that the Burenkova approach may not provide accurate predictions for gradations that are uniform in the coarse fraction and broad in the finer fraction, Wan and Fell [28] proposed that the potential for internal instability in these broadly graded soils be evaluated using the same characteristic $D_{90} / D_{60}$ value for the coarser fraction but with a value of $D_{20} / D_{5}$ for the finer fraction. The distribution of gradations is shown in Figure 11 .

A summary of the analyses (Table 4) for the most vulnerable core gradation shows that the Wan-Fell alternative method predicts that none of the gradations are potentially unstable (located in the unstable or transition region).

\section{Discussion}

Although the soils investigated by Kenney and Lau [15] are cohesionless sand and gravels without fines, experimental observations indicate that the Kenney-Lau method may also apply to soils that have a fraction of non-plastic silt [10] [30] [38]. In addition, the Li and Fannin [27] adaptation of the Kenney-Lau approach to broadly graded soils with some fines appears to be more reliable [38] [39] and provide a less conservative analysis 


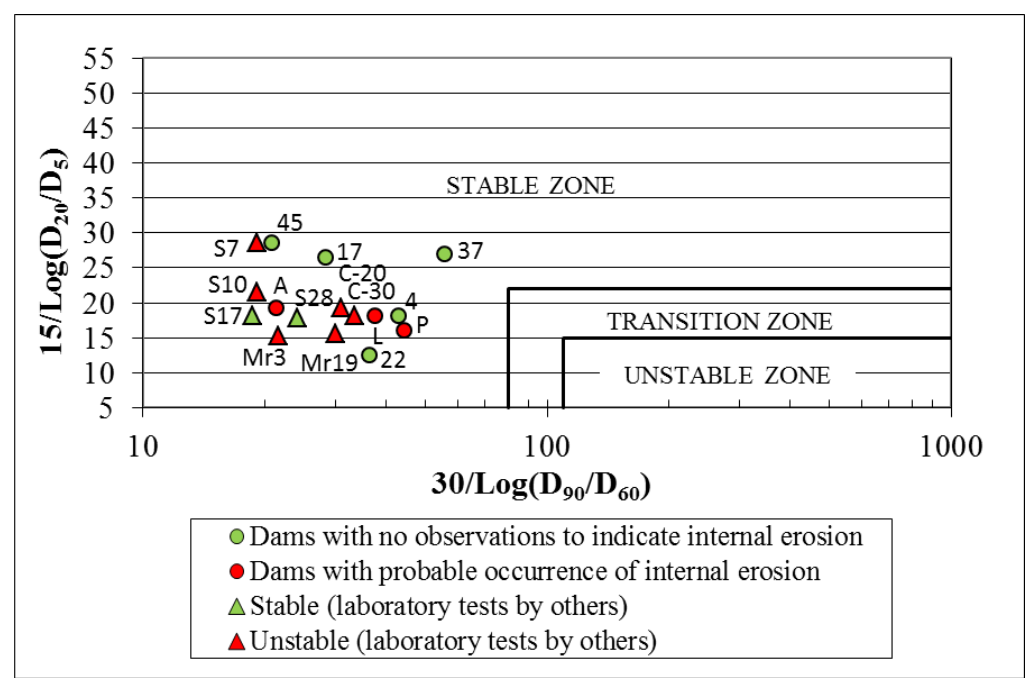

Figure 11. Distribution of gradations obtained by applying the Wan-Fell alternative method for broadly graded soils (gradations RD, FG1, CG3, S, N, 11, 26 and 54 are not included due to data on minus \#200 sieve are not available).

[14]. However, Burenkova [17] tested some silt-sand-gravel soils, and Wan and Fell [22], who adapted the Burenkova method, focused on broadly graded soils that contain silt and clay.

The comparative analysis indicates that both the Kenney-Lau approach and the Burenkova method have merit in terms evaluating the internal stability of glacial till gradations, and a closer analysis indicates that the Kenney-Lau method has better predictive ability, particularly with its Li-Fannin adaptation (Table 4). However, the Wan-Fell adaptation [22] (Figure 10) and the Wan-Fell alternative method [28] (Figure 11) appear to be less successful for glacial till gradations. Figure 12 compiles the 20 gradations that Wan-Fell tested and based their methods on; unstable results in the UNSW tests are shown as red lines in the particle size distributions, while stable are shown as green lines. Although the tested soils include a wide range of gradations, they are mostly gap-graded or steep-sloped in the coarser fraction and flat in the finer, which is relatively uncharacteristic of the typically smooth gradations of the well-graded glacial tills investigated in this paper (compare with Figure 5 and Figure 6). This may indicate the potentially limited predictive ability of these methods for glacial till gradations.

Interestingly, neither the Kenney-Lau approach nor the Burenkova successfully identifies the unstable gradations S7 and S10 that were tested by Lafleur and Nguyen [8] (Figure 5, Table 4). Lafleur and Nguyen [8] argued that a glacial till sample would gradually become more susceptible to suffusion with decreasing fines content (which increases the upward concavity of the grading, thus potentially making it unstable). They found that over time, the fines-poor samples ultimately showed a loss of head near the filter interface (Figure 13(a)), whereas the fines-rich samples exhibited a uniform head loss through the sample (Figure 13(b)). The head loss in the fines-poor gradations was caused by the accumulation of migrating particles from clogging, and the migration of particles was possible due to internal instability. In contrast, the fines-rich samples behaved the same over time and showed no changes in gradation; thus, they were internally stable. Lafleur and Nguyen [8] used a relatively fine-grained filter (i.e., filter paper with an opening size of $0.011 \mathrm{~mm}$, which corresponds approximately to $\mathrm{D}_{15}=0.1 \mathrm{~mm}$ ) as the interface with the glacial till. This would result in a "closed system that prevents loss of particles" [15]. In their internal stability tests, Kenney and Lau [15] [16] abandoned the closed system for an open system to allow unrestricted seepage from the base through the filter. They found that the open system facilitated the monitoring and the subsequent interpretation of the tests. Furthermore, Kenney and Lau [15] usually found that unstable soil exhibited a top transition zone, a central homogenous zone, and a bottom transition zone [15]. Thus, Kenney and Lau [15] concluded that any coarsening of the top transition zone proved the existence of loose movable particles, whereas Lafleur and Nguyen [8] interpreted head loss against the filter (due to accumulation of migrating fines) and increase in fines content as indications of internal instability. In the specimens determined as unstable by Lafleur and Nguyen [8], namely the glacial tills with fines less than $12 \%$ (at a $D_{\max }$ of $38 \mathrm{~mm}$ ), the fines content increased at the most from an initial $4 \%$ to $8 \%$ and for the specimen $\mathrm{S} 10$ analyzed herein from $10 \%$ to $13 \%$ (Figure 13(c)), thus a relatively small change. It is possible that the methods 


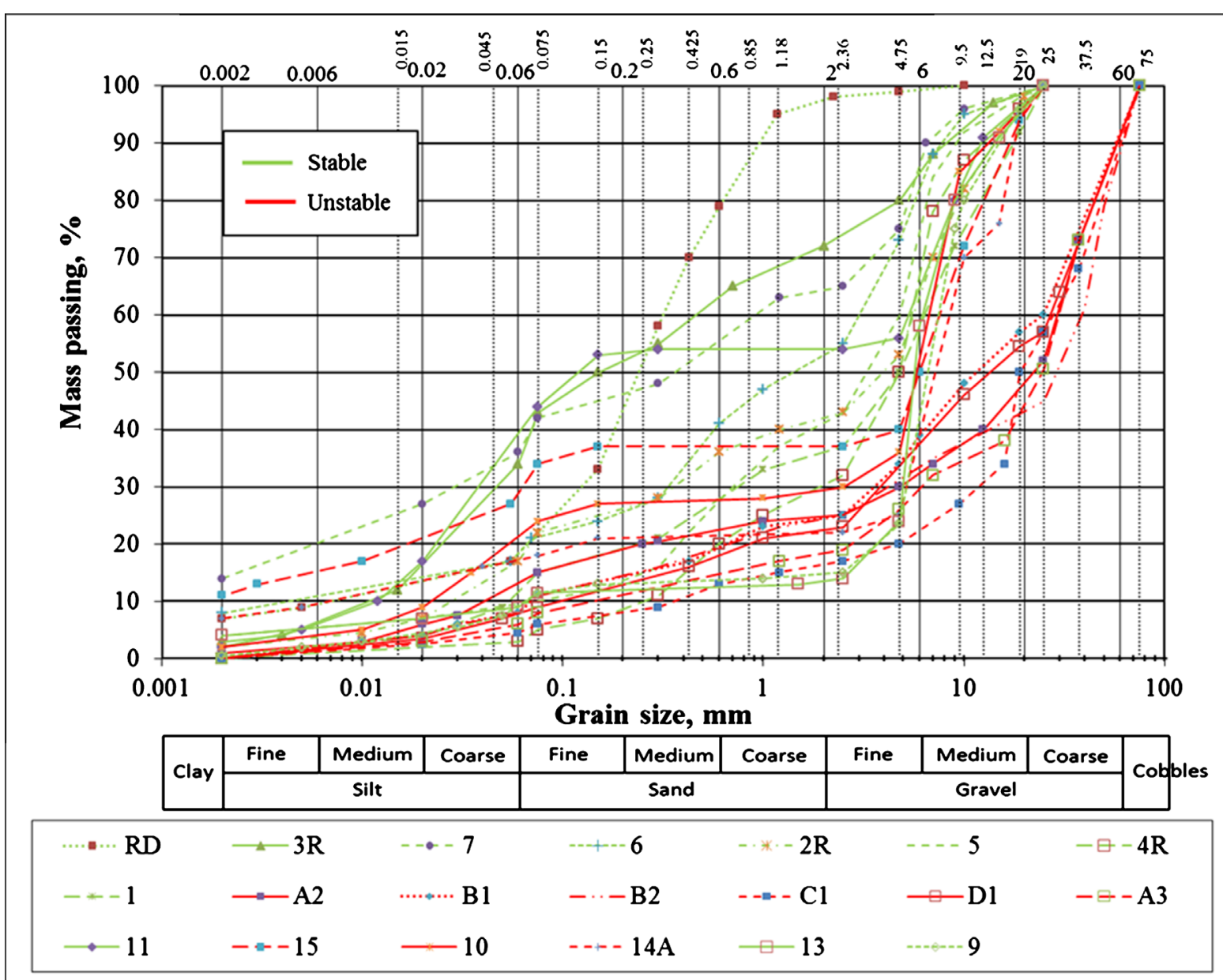

Figure 12. Compilation of gradations tested by Wan-Fell and UNSW (adapted after [9]).

investigated in this study are too crude to identify instability from such a minute change in gradation.

An inspection of the shapes of the gradations investigated in this study reveals that S17, S28, RD, FG1, Mr19 and 22 (Figure 5, Figure 6) have finer fraction in excess of 35\% and thus are potentially not susceptible to suffusion (Table 1 and Table 2). When these samples are excluded, the predictive ability of the methods generally increases, most notably for the Li-Fannin adaptation because it identifies $73 \%$ of the unstable gradations and determines that $89 \%$ of the potentially unstable gradations are gradations that have tested or performed as unstable (Table 4). Figure 14 shows a plot of the stability indexes $(\mathrm{H} / \mathrm{F})_{\min }$ when gradations with finer fractions $>35 \%$ are excluded.

\section{Conclusion}

This paper investigates the applicability of available empirical methods for assessing the internal stability of glacial tills. A database of 24 gradations was compiled. The database incorporates experimental gradations from laboratory studies in the literature and selected gradations from existing dams, some of which have experienced internal erosion. Internal instability may cause suffusion, which is an initiation mechanism of internal erosion. Two approaches are used to evaluate the internal stability: the Kenney-Lau method [15] [16], which analyses the shape of the gradation curve; and the Burenkova method [17], which uses characteristic values of the slope of the gradation (factors of uniformity). The shape analysis of the gradations and the comparative analysis of the methods presented in this study indicate that both the Kenney-Lau method and the Burenkova method have merit, but a closer analysis indicates that the Kenney-Lau method has relatively better predictive ability based on the glacial till gradations analyzed in this study; when the Li-Fannin [27] adaptation is used, 73\% of the unstable 


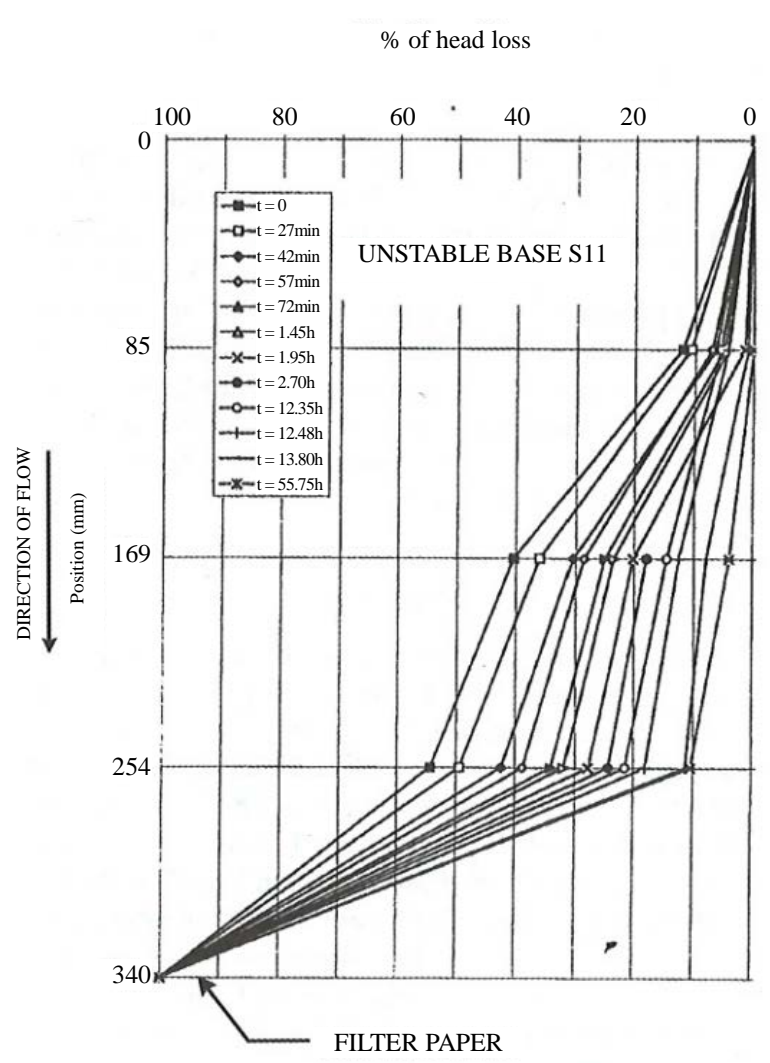

(a)

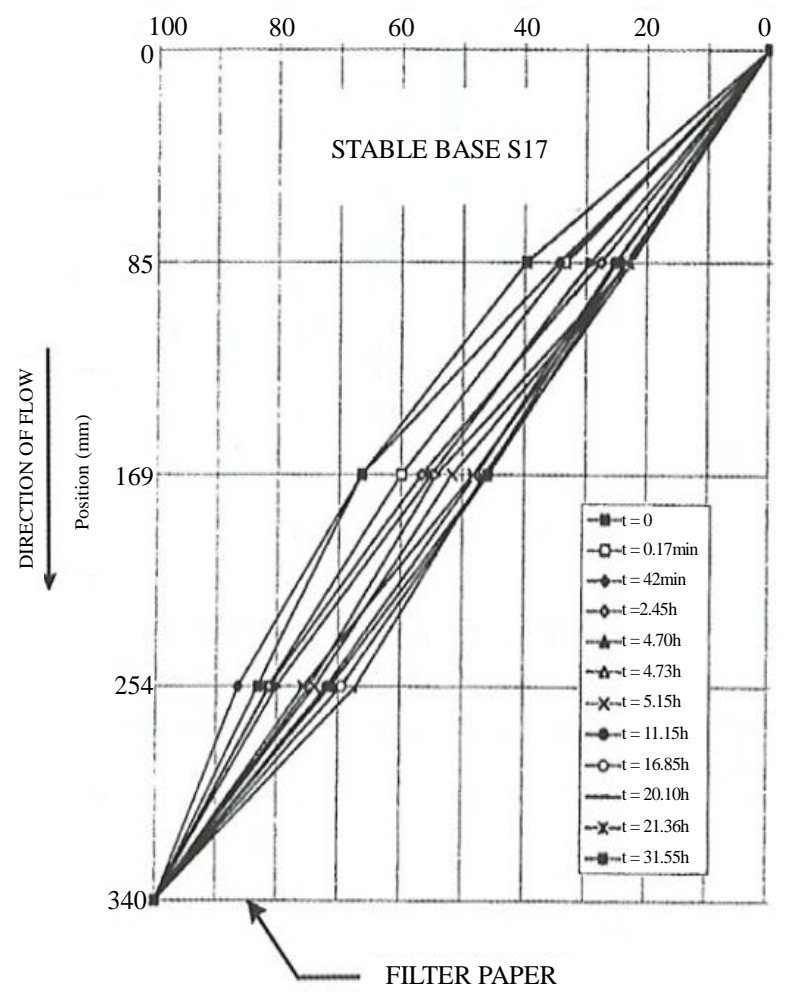

(b)

$\%$ of lines

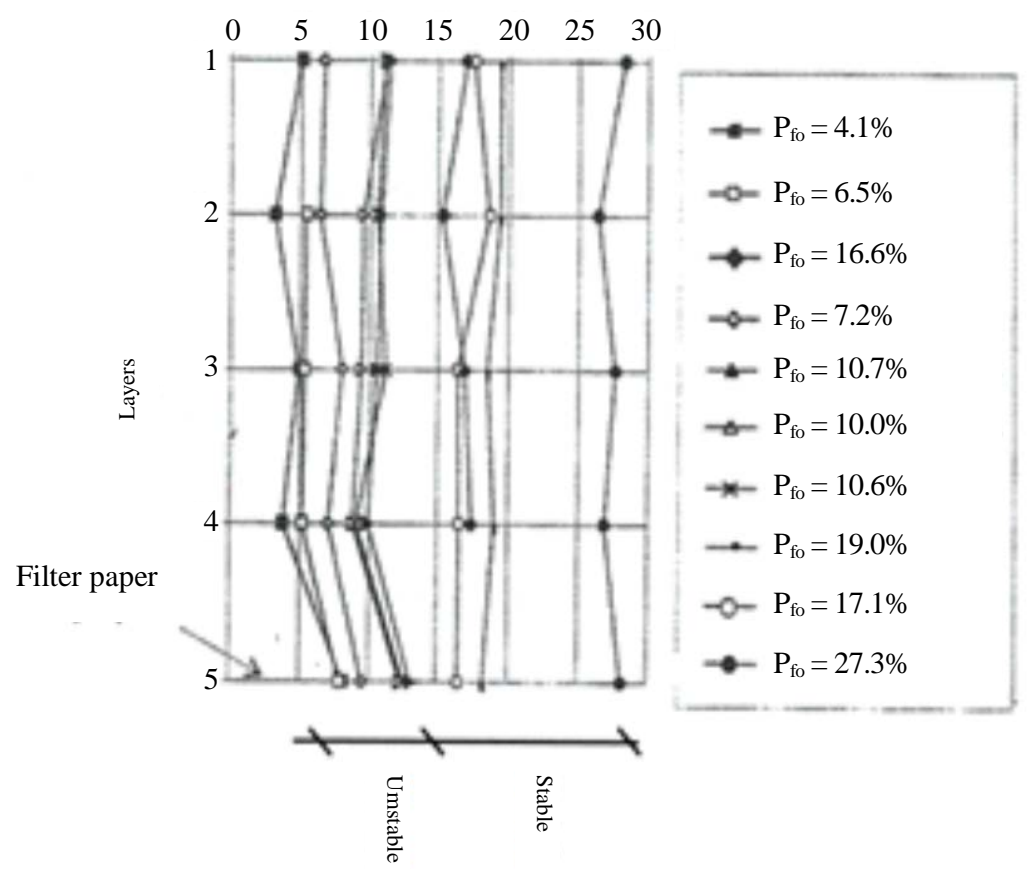

(c)

Figure 13. Suffusion tests by Lafleur-Nguyen showing head losses over time for (a) internally unstable base S11, (b) internally stable base S17, and (c) change in fines content for stable and unstable till specimens (adapted after [8]). 


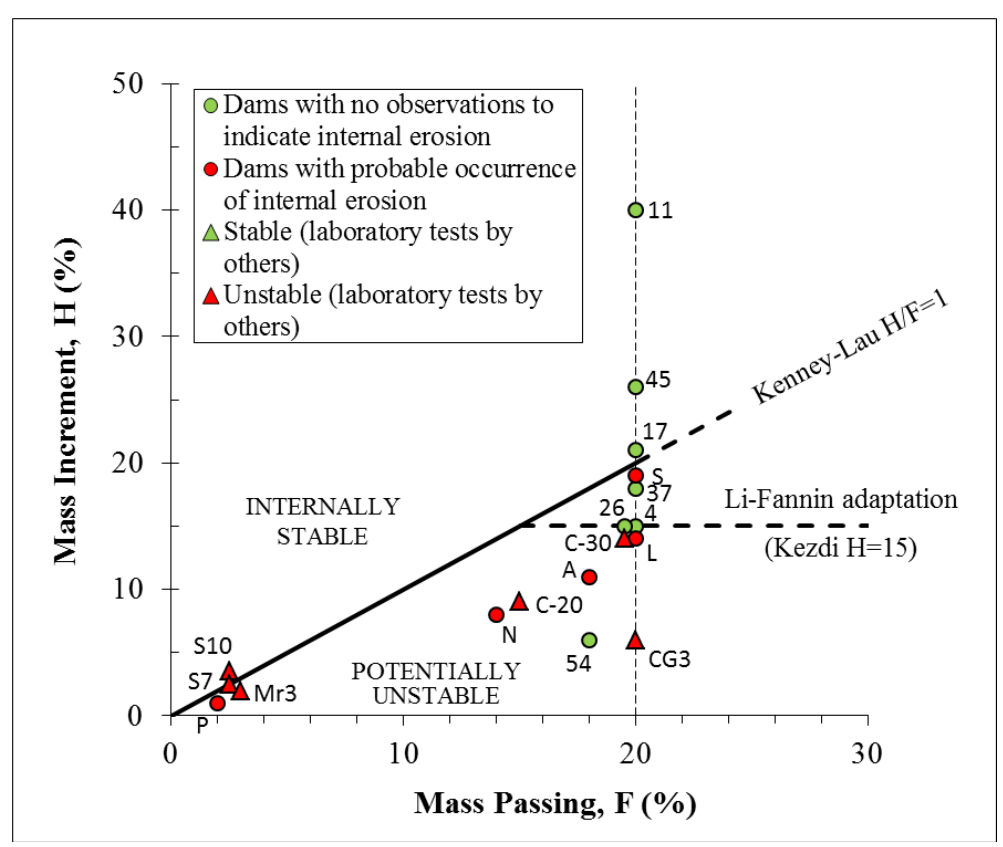

Figure 14. Plot of stability indexes $(\mathrm{H} / \mathrm{F})_{\min }$ when excluding gradations with finer fraction $>35 \%$.

gradations are identified and it determines that $89 \%$ of the potentially unstable gradations are gradations that tested or performed unstable (Figure 14).

\section{Acknowledgements}

The research presented was carried out as part of the "Swedish Hydropower Centre-SVC". SVC has been established by the Swedish Energy Agency, Elforsk and Svenska Kraftnät together with Luleå University of Technology, the Royal Institute of Technology, Chalmers University of Technology and Uppsala University.

The authors acknowledge with gratitude the financial support received from WSP Sweden.

\section{References}

[1] Bernell, L. (1976) Control of Leakage through Dams Founded on Glacial Till Deposits. Proceedings of 12th ICOLD Congress, International Commission on Large Dams, Mexico, 937-950.

[2] Bernell, L. (1982) Experiences of Wet Compacted Dams in Sweden. Proceedings of 14th ICOLD Congress, International Commission on Large Dams, Rio de Janeiro, 421-431.

[3] Foster, M., Fell, R. and Spannagle, M. (2000) The Statistics of Embankment Dam Failures and Accidents. Canadian Geotechnical Journal, 37, 1000-1024. http://dx.doi.org/10.1139/t00-030

[4] Nilsson, Å., Ekström, I. and Söder, C. (1999) Sinkholes in Swedish Embankment Dams. Elforsk Report, 99, 34.

[5] Rönnqvist, H. (2009) Long-Term Behaviour of Internal Erosion Afflicted Dams Comprising Broadly Graded Soils. Dam Engineering, 20, 149-197.

[6] ICOLD (2013) Internal Erosion of Existing Dams, Levees and Dykes, and Their Foundations. In: Bridle, R. and Fell, R., Eds., Bulletin 164, Volume 1: Internal Erosion Processes and Engineering Assessment, International Commission on Large Dams, Paris.

[7] Sherard, J.L. (1979) Sinkholes in Dams of Coarse, Broadly Graded Soils. Proceedings of 13th ICOLD Congress, Vol. II, International Commission on Large Dams, India, 25-35.

[8] Lafleur, J. and Nguyen, P.H. (2007) Internal Stability of Particles in Dam Cores Made of Cohesionless Broadly Graded Moraines. Internal Erosion of Dams and Their Foundations, Taylor \& Francis, UK, 151-158.

[9] Wan, C.F. (2006) Experimental Investigations of Piping Erosion and Suffusion of Soils in Embankment Dams and Their Foundations. Ph.D. Thesis, University of New South Wales, Sydney.

[10] Moffat, R., Fannin, R.J. and Garner, S. (2011) Spatial and Temporal Progression of Internal Erosion in Cohesionless 
Soil. Canadian Geotechnical Journal, 48, 399-412. http://dx.doi.org/10.1139/T10-071

[11] Hunter, G., Fell, R. and Topham, C. (2012) Backward Erosion Piping: What Are the Chances of That? Proceedings of ANCOLD 2012, Perth, 24-28 October 2012.

[12] Lilja, H.M., Rother, M. and Ravaska, O.T. (1998) Filter Material Study for an Earth Dam Project. In: Berga, L., Ed., Dam Safety, Balkema, 825-832.

[13] Rönnqvist, H. and Viklander, P. (2014) Laboratory Testing of Internal Stability of Glacial Till, a Review. Electronic Journal of Geotechnical Engineering, 19, 6315-6336.

[14] Rönnqvist, H. and Viklander, P. (2014) Extending the Kenney-Lau Method to Dam Core Soils of Glacial Till. Geotechnical Research, 1, 73-87.

[15] Kenney, T.C. and Lau, D. (1985) Internal Stability of Granular Filters. Canadian Geotechnical Journal, 22, $215-225$. http://dx.doi.org/10.1139/t85-029

[16] Kenney, T.C. and Lau, D. (1986) Internal Stability of Granular Filters: Reply. Canadian Geotechnical Journal, 23, 420-423. http://dx.doi.org/10.1139/t86-068

[17] Burenkova, V.V. (1993) Assessment of Suffusion in Non-Cohesive and Graded Soils. In: Brauns, J., Schuler, U. and Heibum, M., Eds., Proceedings of the 1st International Conference “Geo-Filters”, Filters in Geotechnical Engineering, Balkema, 357-360.

[18] ICOLD (1989) Moraine as Embankment and Foundation Material—State of the Art. Bulletin 69, International Commission on Large Dams, Paris.

[19] Milligan, V. (2003) Some Uncertainties in Embankment Dam Engineering. Journal of Geotechnical and Geoenvironmental Engineering, ASCE, 129, 785-797. http://dx.doi.org/10.1061/(ASCE)1090-0241(2003)129:9(785)

[20] Vaughan, P.H. and Soares, H.F. (1982) Design of Filters for Clay Cores of Dams. Journal of the Geotechnical Engineering, ASCE, 108, 17-31.

[21] Sherard, J.L. and Dunnigan, L.P. (1989) Critical Filters for Impervious Soils. Journal of Geotechnical Engineering, ASCE, 115, 927-947. http://dx.doi.org/10.1061/(ASCE)0733-9410(1989)115:7(927)

[22] Wan, C.F. and Fell, R. (2004) Experimental Investigation of Internal Instability of Soils in Embankment Dams and Their Foundation. UNICIV Report No. 429, The University of New South Wales, Kensington.

[23] Skempton, A.W. and Brogan, J.M. (1994) Experiments on Piping in Sandy Gravels. Géotechnique, 44, 449-460. http://dx.doi.org/10.1680/geot.1994.44.3.449

[24] Garner, S.J. and Sobkowicz, J.C. (2002) Internal Instability in Gap-Graded Cores and Filters. Proceedings of 2002 Annual CDA Conference, Canadian Dam Association, Victoria.

[25] Kezdi, A. (1979) Soil Physics—Selected Topics. Elsevier Scientific Publishing Co., Amsterdam, 160 p.

[26] USACE (1953) Filter Experiments and Design Criteria. Technical Memorandum No. 3-360, Waterways Experiment Station, Vicksburg.

[27] Li, M. and Fannin, R.J. (2008) Comparison of Two Criteria for Internal Stability of Granular Soil. Canadian Geotechnical Journal, 45, 1303-1309. http://dx.doi.org/10.1139/T08-046

[28] Wan, C.F. and Fell, R. (2008) Assessing the Potential of Internal Instability and Suffusion in Embankment Dams and Their Foundations. Journal of Geotechnical and Geoenvironmental Engineering, 134, 401-407. http://dx.doi.org/10.1061/(ASCE)1090-0241(2008)134:3(401)

[29] Rönnqvist, H. and Viklander, P. (2014) On the Kenney-Lau Approach to Internal Stability Evaluation of Soils. Geomaterials, 4, 129-140.

[30] Moffat, R. and Fannin, R.J. (2011) A Hydromechanical Relation Governing Internal Stability of Cohesionless Soil. Canadian Geotechnical Journal, 48, 413-424. http://dx.doi.org/10.1139/T10-070

[31] Foster, M.A. and Fell, R. (2001) Assessing Embankment Dam Filters That Do Not Satisfy Design Criteria. Journal of Geotechnical and Geoenvironmental Engineering, 127, 398-407. http://dx.doi.org/10.1061/(ASCE)1090-0241(2001)127:5(398)

[32] Wood, D., Kjaernsli, B. and Höeg, K. (1976) Thoughts Concerning the Unusual Behavior of Hyttejuvet Dam. Proceedings of ICOLD 12th Congress, International Commission on Large Dams, Mexico, 391-414.

[33] Sherard, J.L. (1973) Embankment Dam Cracking. In: Hirschfeld, R.C. and Poulos, S.J., Eds., Embankment-Dam Engineering (Casagrande Volume), John Wiley, New York, 324-328.

[34] Ericsson, J. and Jender, M. (1998) Documentation and Investigation of Damages in Lövön Dam. Master's Thesis, Luleå University of Technology, Luleå.

[35] Vestad, H. (1976) Viddalsvatn Dam a History of Leakages and Investigations. Proceedings of 12th ICOLD Congress, International Commission on Large Dams, Mexico, 369-390. 
[36] Bartsch, M., Bono, N., Nilsson, Å. and Norstedt, U. (2006) Alternative Measures to Improve the Resistance Against Internal Erosion-Upgrading of the Suorva and the Porjus Rockfill Dams. Proceedings of ICOLD 22nd Congress, International Commission on Large Dams, Barcelona, 207-228.

[37] Torblaa, I. and Rikartsen, C. (1997) Songa, Sudden Variations of the Leakage in a 35 Years Old Rockfill Dam. Proceedings of 19th ICOLD Congress, International Commission on Large Dams, Florence, 255-267.

[38] Li, M., Fannin, R.J. and Garner, S.J. (2009) Application of a New Criterion for Assessing the Susceptibility to Internal Erosion. Proceedings of CDA 2009, Canadian Dam Association, Whistler, 3-8 October 2009.

[39] Li, M., Fannin, R.J. and Anderlini, C. (2014) Assessing Performance of a Potentially Internally Unstable Filter. Proceedings of CDA 2014, Canadian Dam Association, Banff, 4-9 October 2014.

\section{Notations}

D: grain size (mm);

F: amount of mass passing at grain size $\mathrm{D}(\%)$;

$\mathrm{H}$ : mass increment between $\mathrm{D}$ and $4 \mathrm{D}(\%)$;

$\mathrm{D}_{\max }$ : maximum particle size of gradation (mm);

$\mathrm{C}_{\mathrm{u}}$ : coefficient of uniformity, $\mathrm{d}_{60} / \mathrm{d}_{10}$;

$(\mathrm{H} / \mathrm{F})_{\min }$ : stability index, defined by the smallest value of $\mathrm{H} / \mathrm{F}$, for $0<\mathrm{F} \leq 20 \%$ in soil with a widely graded coarse fraction and $0<\mathrm{F} \leq 30 \%$ in soils that are narrowly graded. 
Scientific Research Publishing (SCIRP) is one of the largest Open Access journal publishers. It is currently publishing more than 200 open access, online, peer-reviewed journals covering a wide range of academic disciplines. SCIRP serves the worldwide academic communities and contributes to the progress and application of science with its publication.

Other selected journals from SCIRP are listed as below. Submit your manuscript to us via either submit@scirp.org or Online Submission Portal.
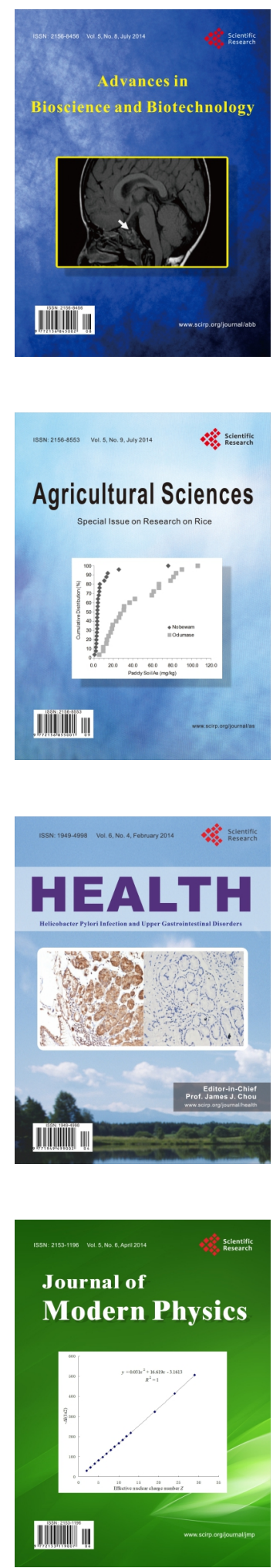
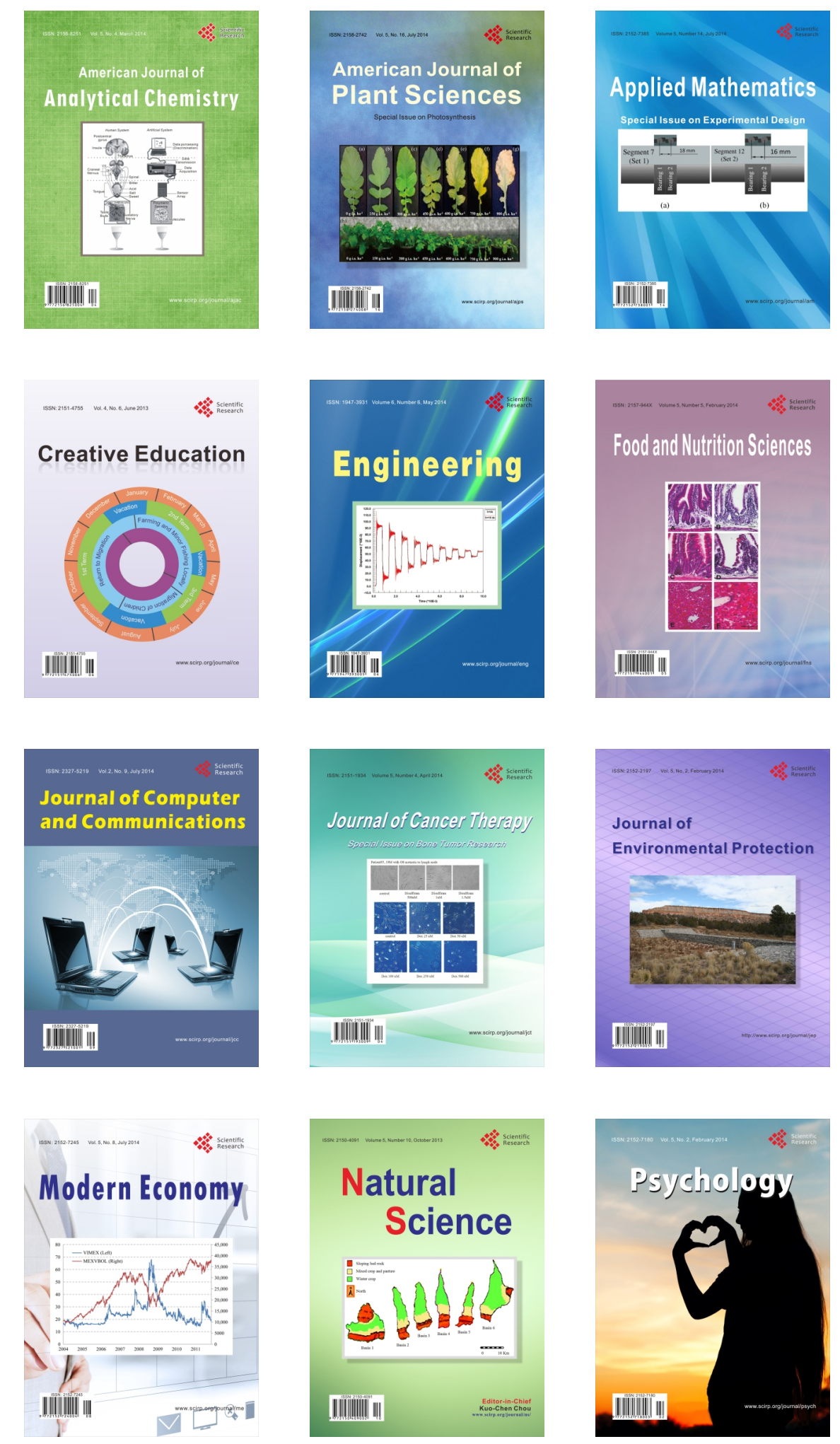